\title{
Inflammatory Response in the First 48 Hours of Acute Ischemic Stroke
}

\author{
Arnon Blum ${ }^{\mathrm{a}, \mathrm{d}}$, Samah Haiek ${ }^{\mathrm{b}}$, Vladimir Vaispapir ${ }^{\mathrm{c}}$
}

\begin{abstract}
Background: Activation of endothelial cells is an important mediator of atherothrombosis. Markers of endothelial cells such as soluble adhesion molecules can be measured in plasma and reflect the activity of the endothelium and the inflammatory system. We hypothesized that patients with acute ischemic stroke would have a dynamic change in their markers of inflammation over time, primarily reflecting the activation of endothelial cells and the immunological ability to respond to an acute brain insult. We also believed that the acute inflammatory response in the first 72 hours might affect the short and long term clinical outcome.
\end{abstract}

Methods: We conducted a prospective case study of 27 patients that were admitted with acute ischemic stroke during the years 2005 - 2007. All were examined clinically using the National Institute of Health Stroke Scale [NIHSS] and a brain computed tomography (CT) scan was done in the first 24 hours. Blood was drawn for levels of E-selectin, intracellular adhesion molecule 1 (ICAM-1), and vascular cellular adhesion molecule 1 (VCAM-1) on admission and 48 hours later by ELISA methods. The blood was separated and the serum was frozen at $-80^{\circ} \mathrm{C}$ until analyzed as one batch.

Results: Mean blood concentrations of soluble E-selectin, intracellular adhesion molecule 1 (ICAM-1), and vascular cell adhesion molecule 1 (VCAM-1) were measured on admission and 48 hours later. Clinically there were 3 groups: 6 patients with transient ischemic attack [TIA] (58 \pm 12 years old, 3 women and 3 men $), 8$ pa-

Manuscript accepted for publication January 18, 2011

a Department of Medicine, the Research Biochemical Laboratory, Baruch Padeh Poria Medical Center, Lower Galilee, Israel

${ }^{\mathrm{b}}$ Epidemiological Department, School of Public Health, Haifa University, Haifa, Israel

${ }^{\mathrm{c}}$ Department of Medicine, the Neurological Unit, Baruch Padeh Poria Medical Center, Lower Galilee, Israel

${ }^{\mathrm{d}}$ Corresponding author: Arnon Blum, Department of Medicine, Lower

Galilee 15208, Israel. Email: navablum@hotmail.com

doi:10.4021/jnr101e tients with cerebrovascular accident [CVA] without recovery $(75 \pm$ 18 years old, 4 women and 4 men), and 13 patients with CVA who recovered clinically $(70 \pm 13$ years old, 6 women and $7 \mathrm{men})$. There was a significant increase in E-selectin levels in the second measurement (from $27.5 \pm 21.6 \mathrm{ng} / \mathrm{ml}$ to $38.7 \pm 19.6 \mathrm{ng} / \mathrm{ml} ; \mathrm{Z}=-1.997$, $\mathrm{P}=0.046$ ) in the TIA group. An inverse correlation was found between E-selectin level and age among TIA patients on admission $(\mathrm{r}=-0.913, \mathrm{P}=0.011)$ and 48 hours later $(\mathrm{r}=-0.850, \mathrm{P}=0.032)$. A positive correlation between ICAM-1 and VCAM-1 levels was found 48 hours post admission $(\mathrm{r}=0.436, \mathrm{P}=0.026)$.

Conclusions: We have demonstrated a significant increase in Eselectin level within 48 hours among patients with TIA. In the TIA group there was an inverse correlation between age and E-selectin level. This may suggest that younger patients can protect their ischemic brain more efficiently due to a more competent immune system, and that the immune system may have an important role in ischemic brain injury.

Keywords: Endothelial activation; E-selectin; Acute ischemic stroke; Age and immunity

\section{Introduction}

Atherothromboembolic ischemic stroke is believed to be the product of long standing vascular inflammation, plaque rupture, thrombosis and brain ischemia or infarction [1].

E-selectin belongs to the family of adhesion molecules that are trans-membrane glycoproteins that are expressed solely on activated endothelial cells. Their role is believed to be "rolling" of leukocytes, slowing down leukocytes in the circulation and attracting them to the endothelium [1-13]. After a while (24 - 72 hours) the leukocytes start to adhere to the endothelium through the action of another family of cell adhesion molecules, the immunoglobulin family including intercellular adhesion molecule 1 (ICAM-1) and vascular cell adhesion molecule 1 (VCAM-1) [1]. There is a gradual process of activation of the immune system through activation of adhesion molecules, starting with E-selectin activation on endothelial cells (rolling of leukocytes) and then firm adhesion of leukocytes to the endothelium through activa- 
Table 1. Baseline Demographics According to Clinical Definition and NIHSS on Admission (A) and 48 Hours Later (B)

\begin{tabular}{|c|c|c|c|c|}
\hline & TIA & CVA with recovery & CVA without recovery & P-value \\
\hline Age $($ Mean \pm SD $)$ & $58 \pm 12$ & $70 \pm 13$ & $75 \pm 18$ & NS \\
\hline Women & 3 & 6 & 6 & \\
\hline Men & 3 & 7 & 7 & \\
\hline \multirow[t]{2}{*}{ NIHSS A } & 0 & $5.5 \pm 3.1$ & $6.4 \pm 5.1$ & \\
\hline & & * & $\wedge$ & \\
\hline NIHSS B & 0 & $3.2 \pm 3.5$ & $7.4 \pm 4.9$ & \\
\hline
\end{tabular}

* $: Z=-3.207, P=0.001$

$\wedge: Z=-1.342, P=0.180$

NIHSS A = national institutes of health neurological scale at time zero (on admission)

NIHSS B $=$ national institutes of health neurological scale after 48 hours

tion of ICAM-1 and VCAM-1.

When arterial thrombosis causes ischemic neuronal death, several cytokines are released from damaged neurons (tumor necrosis factor $\alpha$ and interleukin-1) that enhance the expression of E-selectins on endothelial cells in the brain. E-selectin molecules attract leukocytes into the ischemic region and start a reperfusion injury $[14,15]$. Leukocytes are believed to produce reactive oxygen species in the ischemic brain and promote further inflammatory and self-defense processes in the ischemic penumbra [16, 17].

Soluble cell adhesion molecules play active role in the pathophysiology of atherosclerotic ischemic stroke and our purpose was to study the cascade of the inflammatory events over the first 72 hours since admission to the hospital with acute ischemic stroke.

\section{Methods}

\section{Cases}

Inclusion criteria: consecutive patients that were admitted with acute cerebral stroke between the years 2005 - 2007 and were conscious and comprehensive were approached for consent to participate in this study.

Exclusion criteria: patients that were admitted with coma or semi-coma, or patients that were confused. Patients younger than 18 years were also excluded. Patients that had an acute hemorrhagic stroke were excluded from the study. Other exclusion criteria included pregnant women, a known malignancy, acute or chronic renal failure, a chronic inflammatory or an immunological disease, acute myocardial in- farction or unstable angina pectoris, acute or chronic heart failure, patients with cardiomyopathy, patient who had recent (within 3 months) vascular intervention, any kind of surgery within the last 6 months, or had acute (within 3 months) or chronic infectious illness.

Ischemic stroke was defined as a clinical stroke syndrome (that started within the last 24 hours) with either a normal computed tomography (CT) brain scan or a recent infarct in the clinically relevant area of the brain. At baseline every patient was evaluated by a Neurologist and was consented before participation in the study. The Neurologist estimated the NIH stroke scale and treatment with aspirin and statins started within the first 3 hours of admission. None of the enrolled patients needed a thrombolytic therapy or an acute vascular intervention.

Every patient underwent a brain CT within the first few hours of admission and was examined by the Neurologist. Patients were classified according to the clinical NIH stroke scale (NIHSS).

Every patient had the first neurological evaluation in the first 24 hours of admission and another neurological evaluation was done using the national institutes of health stroke scale within the next 48 hours.

Blood was drawn twice, in the first 24 hours of admission and again within the next 48 hours, was separated and frozen at $-80^{\circ} \mathrm{C}$ until processed as one batch in the end of the study. The first blood drawing was usually $16-20$ hours after symptom onset and the second blood drawing was 48 hours later.

Stroke with recovery was defined as an acute ischemic event that improved even slightly according the NIHSS. Stroke without recovery was defined as a stroke that was not 
Table 2. NIHSS, E-selctin, ICAM-1, VCAM-1 Levels at Baseline (A) and 48 Hours After Acute Stroke (B)

\begin{tabular}{|c|c|c|c|}
\hline & TIA & CVA with recovery & CVA without recovery \\
\hline NIHSS A & 0 & $5.5 \pm 3.1$ & $6.4 \pm 5.1$ \\
\hline NIHSS B & 0 & $3.2 \pm 3.5$ & $7.4 \pm 4.9$ \\
\hline $\mathrm{Z}$ & 0 & -3.207 & 1.342 \\
\hline P-value & 1.0 & 0.001 & 0.180 \\
\hline E-selectin A (ng/ml) & $27.5 \pm 21.6$ & $23.4 \pm 13.1$ & $25.4 \pm 21.3$ \\
\hline E-selectin B (ng/ml) & $38.7 \pm 19.6$ & $28.7 \pm 12.8$ & $31.8 \pm 22.5$ \\
\hline Z & -1.997 & 1.847 & 0.841 \\
\hline P-value & 0.046 & 0.065 & 0.400 \\
\hline ICAM-1 A (ng/ml) & $386.7 \pm 86.4$ & $398.3 \pm 120.7$ & $371.4 \pm 53.0$ \\
\hline ICAM-1 B (ng/ml) & $343.5 \pm 185.8$ & $429.2 \pm 112.2$ & $385.7 \pm 123.8$ \\
\hline $\mathrm{Z}$ & -0.105 & 1.365 & 0.169 \\
\hline P-value & 0.916 & 0.172 & 0.866 \\
\hline VCAM-1 A (ng/ml) & $702.8 \pm 163.9$ & $1026.7 \pm 432.5$ & $771.4 \pm 282.2$ \\
\hline VCAM-1 B (ng/ml) & $723.2 \pm 182.4$ & $968.5 \pm 421.9$ & $815.1 \pm 320.5$ \\
\hline $\mathrm{Z}$ & 0.524 & -1.101 & 1.342 \\
\hline P-value & 0.600 & 0.271 & 0.180 \\
\hline
\end{tabular}

improved at all or got worse by the NIHSS, and transient ischemic attack was defined as a neurological event that disappeared without any squeal in the first 24 hours after symptom onset.

The serum was examined for levels of cell adhesion molecules, E-selectin, intercellular adhesion molecule 1 (ICAM-1), and vascular cell adhesion molecule 1 (VCAM1) by ELISA methods (R\&D Systems, Inc.; Minneapolis, MN 55413, USA).

\section{Statistical analysis}

All analyses were based on available data. The distribution of values of the adhesion molecules was not perfectly normal. We performed nonparametric tests, Wilcoxon Sign Rank test and Kreuskall-Wallis test. The significance of any relationship between blood concentrations of E-selectin, ICAM-1, and VCAM-1 and age was examined by Pearson's correlation coefficient.

We used SPSS version 15 to analyze the data. Signifi- cance was defined as less than $5 \%$ for each test ( $\mathrm{P}$ value $\leq$ $0.05)$.

\section{Results}

Twenty-seven patients were admitted with acute ischemic stroke. The arrival time was between 2 - 8 hours from symptom onset, and the first blood drawing was in the first 24 hours, usually 16 - 20 hours after symptom onset.

Clinically there were 3 groups: 6 patients with transient ischemic attack [TIA] $(58 \pm 12$ years old, 3 women and 3 men), 8 patients with cerebrovascular accident [CVA] without recovery ( $75 \pm 18$ years old, 4 women and 4 men), and 13 patients with CVA who recovered clinically $(70 \pm 13$ years old, 6 women and 7 men) (Table 1).

Even though patients in the TIA group were younger than the other 2 groups and patients in the CVA without recovery group were the oldest, no significant difference in age was observed between the 3 groups or between any of 2 
groups (Table 1).

Only patients who belonged to the CVA with recovery group had changed their NIHSS significantly (from NIHSS $5.5 \pm 3.2$ to $3.2 \pm 3.5 ; \mathrm{Z}=-3.207 ; \mathrm{P}=0.001$ ) (Table 1 ).

The only significant change in any of the soluble cell adhesion molecules was observed in the E-selectin level ( $\mathrm{Z}$ $=-1.997, \mathrm{P}=0.046)$ and it was demonstrated only in the TIA group (Table 2).

An inverse correlation was found between E-selectin level and age among TIA patients on admission $(\mathrm{r}=-0.913$, $\mathrm{P}=0.011)$ and 48 hours later $(\mathrm{r}=-0.850, \mathrm{P}=0.032)$.

A correlation between ICAM-1 and VCAM-1 levels was found 48 hours post admission $(\mathrm{r}=0.436, \mathrm{P}=0.026)$.

\section{Discussion}

The principal findings were that within 48 hours of acute ischemic stroke there are dynamic changes in levels of soluble cell adhesion molecules that can define the clinical outcome.

The change in soluble cell adhesion molecules' profile may reflect the activation of the inflammatory system: first E-selectins are activated, then the immunoglobulin adhesion molecules that continue cells' firm adhesion and transmigration through the endothelium.

There was a strong independent association between increasing blood concentrations of markers of endothelial activation (E-selectins) during the first 48 hours among patients who had TIA. Only patients who could respond by an intense inflammatory burst of soluble E-selectins could survive the acute stroke and the ischemic insult of the brain, and eventually developed only minor neurological insults that were completely reversible. Even though we had such a small sample, still the data may suggest a certain trend or thought that should be further investigated.

Such a response, an increase in E-selectin level in the acute phase was demonstrated in several studies that were published in the last few years. Cherian et al had demonstrated significant associations between acute elevation of markers of endothelial cell activation and acute ischemic stroke [18]. Tuttolomondo et al had demonstrated that interleukin$1 \beta$ and E-selectin were significantly associated with acute ischemic stroke, while interleukin 6, ICAM-1 and VCAM1 showed no association with the acute phase of ischemic stroke [19]. Another study demonstrated that acute ischemic stroke was associated with elevated plasma levels of soluble ICAM-1, soluble VCAM-1, and soluble E-selectin levels, independent of age, sex, and other recognized risk factors for stroke [20]. Other studies have demonstrated the same association of increased levels of soluble E-selectin and soluble P-selectin during the acute and subacute phases of stroke [21, 22].

We have demonstrated that in patients with acute stroke who improved within the first days of hospitalization, levels of soluble cell adhesion molecules (E-selectin, ICAM-1, and VCAM-1) decreased significantly within 4 days. However, patients who did not improve clinically, their levels of soluble cell adhesion molecules did not decrease or even increased further [22].

Another study has shown that a combination of $2 \mathrm{mi}-$ nor alleles of E-selectin genes (alleles R of S128R and F of L554F polymorphisms) appeared to be the strongest susceptibility factor for ischemic stroke [23].

In the present study, we have demonstrated that a significant increase in levels of soluble E-selectin was observed only in patients with TIA. Moreover, an inverse correlation was found between age and levels of E-selectin; thus, it could be that the younger the patient, the more potent his/ her inflammatory system, and it might be that the more intense the acute inflammatory response, the better the clinical outcome.

In this study we tried to estimate the short term clinical outcome. It will be very interesting to correlate these preliminary findings to long term outcome and prognosis.

Is it possible that the ability to produce an intense inflammatory response within 48 hours of acute stroke reflects a more competent immune-defense system?

According to the Eco-immunity theory the immune system and the tissues are two sides of a continuously active and co-evolving predator-prey system (eco-immunity). Eco-immunity views self-tolerance not as an equilibrium in which autoimmunity is chronically suppressed, but as a symmetrical balanced conflict between the ability of immune cells to destroy cells by numerous mechanisms, and the capacity of adapted tissue cells to avoid predation. Thus, whereas some immune cells prey predominantly on pathogens and infected cells, self-reactive cells prey on incompetent tissue cells that fail to express the adapted phenotype and resist predation [24].

\section{Study limitations}

The small number of patients in each group is limiting our power of analysis. On the other hand the very strong statistical findings may suggest that if we had larger numbers in each group we could find much stronger correlations and differences that we missed in this small population.

More studies with much bigger populations are needed in order to validate our results and confirm our conclusions.

\section{Conclusions}

We found that soluble E-selectin level in the peripheral circulation may reflect the ability of the immune system to fight more efficiently the brain tissue's damage caused by an acute ischemic event. The more aggressive the early response, the more effective the clinical outcome. 
We found that younger patients have the ability to produce higher levels of soluble E-selectin within the first 48 hours of an acute stroke, and this trait appears to be an advantage.

\section{Consent}

The institutional review board of the hospital approved this prospective study, and each study participant provided informed consent.

\section{Financial Disclosure}

None

\section{References}

1. Springer TA. Traffic signals for lymphocyte recirculation and leukocyte emigration: the multistep paradigm. Cell 1994;76(2):301-314.

2. Tedder TF, Steeber DA, Chen A, Engel P. The selectins: vascular adhesion molecules. FASEB J 1995;9(10):866873.

3. Davies MJ, Gordon JL, Gearing AJ, Pigott R, Woolf N, Katz D, Kyriakopoulos A. The expression of the adhesion molecules ICAM-1, VCAM-1, PECAM, and E-selectin in human atherosclerosis. J Pathol 1993;171(3):223229.

4. Dong ZM, Chapman SM, Brown AA, Frenette PS, Hynes RO, Wagner DD. The combined role of P- and E-selectins in atherosclerosis. J Clin Invest 1998;102(1):145152.

5. Collins RG, Velji R, Guevara NV, Hicks MJ, Chan L, Beaudet AL. P-Selectin or intercellular adhesion molecule (ICAM)-1 deficiency substantially protects against atherosclerosis in apolipoprotein E-deficient mice. J Exp Med 2000;191(1):189-194.

6. Frijns CJ, Kappelle LJ. Inflammatory cell adhesion molecules in ischemic cerebrovascular disease. Stroke 2002;33(8):2115-2122.

7. Use of anti-ICAM-1 therapy in ischemic stroke: results of the Enlimomab Acute Stroke Trial. Neurology 2001;57(8):1428-1434.

8. Hwang SJ, Ballantyne CM, Sharrett AR, Smith LC, Davis CE, Gotto AM, Jr., Boerwinkle E. Circulating adhesion molecules VCAM-1, ICAM-1, and E-selectin in carotid atherosclerosis and incident coronary heart disease cases: the Atherosclerosis Risk In Communities (ARIC) study. Circulation 1997;96(12):4219-4225.

9. Ridker PM, Hennekens CH, Roitman-Johnson B,
Stampfer MJ, Allen J. Plasma concentration of soluble intercellular adhesion molecule 1 and risks of future myocardial infarction in apparently healthy men. Lancet 1998;351(9096):88-92.

10. Ridker PM, Buring JE, Rifai N. Soluble P-selectin and the risk of future cardiovascular events. Circulation 2001;103(4):491-495.

11. Blankenberg S, Rupprecht HJ, Bickel C, Peetz D, Hafner G, Tiret L, Meyer J. Circulating cell adhesion molecules and death in patients with coronary artery disease. Circulation 2001;104(12):1336-1342.

12. Malik I, Danesh J, Whincup P, Bhatia V, Papacosta O, Walker M, Lennon L, et al. Soluble adhesion molecules and prediction of coronary heart disease: a prospective study and meta-analysis. Lancet 2001;358(9286):971976.

13. Ridker PM. Role of inflammatory biomarkers in prediction of coronary heart disease. Lancet 2001;358(9286):946-948.

14. Huang J, Choudhri TF, Winfree CJ, McTaggart RA, Kiss S, Mocco J, Kim LJ, et al. Postischemic cerebrovascular E-selectin expression mediates tissue injury in murine stroke. Stroke 2000;31(12):3047-3053.

15. del Zoppo GJ, Schmid-Schonbein GW, Mori E, Copeland BR, Chang CM. Polymorphonuclear leukocytes occlude capillaries following middle cerebral artery occlusion and reperfusion in baboons. Stroke 1991;22(10):12761283.

16. Prestigiacomo CJ, Kim SC, Connolly ES, Jr., Liao H, Yan SF, Pinsky DJ. CD18-mediated neutrophil recruitment contributes to the pathogenesis of reperfused but not nonreperfused stroke. Stroke 1999;30(5):1110-1117.

17. Blann AD, Ridker PM, Lip GY. Inflammation, cell adhesion molecules, and stroke: tools in pathophysiology and epidemiology? Stroke 2002;33(9):2141-2143.

18. Cherian P, Hankey GJ, Eikelboom JW, Thom J, Baker RI, McQuillan A, Staton J, et al. Endothelial and platelet activation in acute ischemic stroke and its etiological subtypes. Stroke 2003;34(9):2132-2137.

19. Tuttolomondo A, Pinto A, Corrao S, Di Raimondo D, Fernandez P, Di Sciacca R, Arnao V, et al. Immuno-inflammatory and thrombotic/fibrinolytic variables associated with acute ischemic stroke diagnosis. Atherosclerosis 2009;203(2):503-508.

20. Simundic AM, Basic V, Topic E, Demarin V, Vrkic N, Kunovic B, Stefanovic M, et al. Soluble adhesion molecules in acute ischemic stroke. Clin Invest Med 2004;27(2):86-92.

21. Kozuka K, Kohriyama T, Nomura E, Ikeda J, Kajikawa H, Nakamura S. Endothelial markers and adhesion molecules in acute ischemic stroke--sequential change and differences in stroke subtype. Atherosclerosis 2002;161(1):161-168.

22. Blum A, Khazim K, Merei M, Peleg A, Blum N, Vaispa- 
pir V. The stroke trial - can we predict clinical outcome of patients with ischemic stroke by measuring soluble cell adhesion molecules (CAM)? Eur Cytokine Netw 2006;17(4):295-298.

23. Haidari M, Hajilooi M, Rafiei AR, Rezaii AA, Hoseini- panah SM. E-selectin genetic variation as a susceptibility factor for ischemic stroke. Cerebrovasc Dis 2009;28(1):26-32.

24. Nevo U, Hauben E. Ecoimmunity: immune tolerance by symmetric co-evolution. Evol Dev 2007;9(6):632-642. 